\title{
Important Research Priorities in Intellectual Disability in India: A Public Health Perspective
}

Sir,

Intellectual disability (ID) is a significant public health concern..$^{[1]}$ So far, ID has been perceived as a rehabilitation issue in India, with the focus being on creating an enabling and supporting environment for this population. Most importantly, ID has been treated either as a learning issue or a medical problem. In the past two decades, the mindset of people has changed toward ID. It is now also being perceived as a social problem. Multiple biological, environmental, social, and behavioral determinants at individual, family, and community levels are known to be correlates of the prevalence of ID in India. ${ }^{[2]}$ Similarly, psychosocial, medical, and environmental factors play a crucial role in the rehabilitation of ID people in the country. Research on ID from the public health perspective has been limited in India. Few important public health research concerns are discussed here.

India lacks up-to-date prevalence and incidence estimates of $\mathrm{ID}^{[2]}$ About $1 \%-3 \%$ of the Indian population is considered to have ID. ${ }^{[1]}$ Considering a huge population of 1.3 billion, the difference of $2 \%$ in prevalence is very large with the potential to significantly affect government policies and services for this population. The incidence of ID is unknown. ID is classified into four major categories: mild, moderate, severe, and profound, with the needs of each category being different. Prevalence and incidence estimates of each ID category are highly needed.

The prevalence of ID is decreasing in the USA. However, the prevalence of other developmental disorders, such as autism, has been increasing significantly in the past two decades. $^{[3]}$ Knowledge of the prevalence trend in India will guide future research in identifying, mapping, and understanding the dynamics of the determinants of that condition.

With the advancement of public health, medical services, medical technology, improved nutrition, and living conditions in India, the age of ID people has also increased significantly. ${ }^{[4]}$ Like other developed countries, even now in India, people with ID are living longer. However, this changed scenario is also creating another challenge for their survival and care in older age. Mainly, the care for ID people was provided by their parents, siblings, and close relatives. Parents become much older than previously, thus they face increasing difficulty in taking care of their ID children. Currently, it is not known how the unique needs of the aging ID population in India should be managed precisely because very little is known about the epidemiological pattern of conditions related to their primary disability. Research is therefore needed to explore and develop models of care that fit the needs of the aging and increasing ID population.

Due to improved care, living conditions, and lack of physical activities, the ID populations in developed, and to greater extent in developing countries, are at higher risks for cardiometabolic diseases, such as metabolic syndrome, cardiovascular disease, diabetes, and other chronic diseases. ${ }^{[5-7]}$ The ID population in India may also be at higher risk for the same chronic diseases. If so, to avoid the cost escalations associated with morbidity, there is urgent need to apply public health interventions to map and prevent these diseases among the ID population in India.

In the past three decades, intervention and provision for rehabilitation services have shifted focus largely from institution-based intervention and care to community-based intervention and care for ID people in India, aligning with patterns in developed countries. With this trend, ID people have more opportunities to live in the community and participate in community activities. However, while this change is very positive for ID people in the community, it is also increasing their vulnerability to substance abuse. The same trends are already occurring in developed countries, with rising risk and prevalence of substance abuse among ID people. ${ }^{[8,9]}$ Currently, the prevalence and risk for substance use and abuse among ID people in India are unknown, highlighting the need for efforts to identify and map the epidemiological profiles of the behavior and the indicated correlated conditions early.

People with ID suffer from a higher burden of behavior problems. ${ }^{[10]}$ Behavior problems not only limit learning in this population but also have been associated with the development of long-term psychological problems. Thus, if the behavior problems and psychological vulnerability of this population are not addressed in an appropriate and timely manner, the risk for increased prevalence of mental disorders in this group may escalate. ${ }^{[1]}$ With the already high prevalence of psychiatric comorbidity among this population, a combination with behavior problems is bound to exacerbate the impact on their physical health and the psychosocial burdens on their families. ${ }^{[12]}$ Such needs among ID people should be addressed with community-level ecological models for behavior management. 
With the best available prevalence estimates, about 13-39 million people would be diagnosed with ID in India, with 30 million to over 100 million living with the condition. ${ }^{[2]}$ People with ID suffer from lower cognitive abilities. Their learning abilities are slower than others, and people with ID need more structured approaches to new learning. Existing public health approaches are not compatible with the learning needs of the ID population. ${ }^{[13]}$ Therefore, public health communication and approaches to health promotion including health awareness, education, promotion of healthy behaviors, and prevention of risks and diseases for this population need to be developed, customized, and piloted as a priority.

The community-based intervention model for ID has been found to be significantly effective. The acceptability of such programs has also been high in the communities. ${ }^{[14]}$ The community-based interventional models closely follow social ecological models. ${ }^{[15]}$ Largely, community-based models intervene at individual, family, society, and government levels. ${ }^{[15,16]}$ Such programs should be self-sustainable, but so far, there is no evidence of that success in India. Most programs die once agency support is withdrawn. Evaluation of community-based rehabilitation programs is needed to identify strategic implementation gaps that drive program sustainability needs, and with the objective being to make the programs sustainable. What is needed to make such programs self-sustainable.

\section{Financial support and sponsorship}

Nil.

\section{Conflicts of interest}

There are no conflicts of interest.

\section{Ram Lakhan, Olúgbémiga T. Ekúndayò ${ }^{1}$}

Department of Health and Human Performance, Berea College, Berea, Kentucky, 'Department of Allied Health College of Health Professions, Northern Kentucky University, Highland Heights, Kentucky, USA

Address for correspondence: Dr. Ram Lakhan, Department of Health and Human Performance, Berea College, Berea, Kentucky, USA. E-mail: ramlakhan15@gmail.com

\section{REFERENCES}

1. Maulik PK, Mascarenhas MN, Mathers CD, Dua T, Saxena S. Prevalence of intellectual disability: A meta-analysis of population-based studies. Res Dev Disabil 2011;32:419-36.

2. Lakhan R, Ekúndayò OT, Shahbazi M. An estimation of the prevalence of intellectual disabilities and its association with age in rural and urban populations in India. J Neurosci Rural Pract 2015;6:523-8.

3. McKenzie K, Milton M, Smith G, Ouellette-Kuntz H. Systematic review of the prevalence and incidence of intellectual disabilities:
Current trends and issues. Curr Dev Disord Rep 2016;3:104-15.

4. Shrestha S, Weber G. The situation of older people with intellectual disability in Nepal: A pilot study. J Intellect Dev Disabil 2002;27:242-54.

5. de Winter CF, Bastiaanse LP, Hilgenkamp TI, Evenhuis HM, Echteld MA. Cardiovascular risk factors (diabetes, hypertension, hypercholesterolemia and metabolic syndrome) in older people with intellectual disability: Results of the HA-ID study. Res Dev Disabil 2012;33:1722-31.

6. Lin PY, Lin LP, Lin JD. Hypertension, hyperglycemia, and hyperlipemia among adolescents with intellectual disabilities. Res Dev Disabil 2010;31:545-50.

7. Morin D, Mérineau-Côté J, Ouellette-Kuntz H, Tassé MJ, Kerr M. A comparison of the prevalence of chronic disease among people with and without intellectual disability. Am J Intellect Dev Disabil 2012;117:455-63.

8. Carroll Chapman SL, Wu LT. Substance abuse among individuals with intellectual disabilities. Res Dev Disabil 2012;33:1147-56.

9. Lin E, Balogh R, McGarry C, Selick A, Dobranowski K, Wilton AS, et al. Substance-related and addictive disorders among adults with intellectual and developmental disabilities (IDD): An Ontario population cohort study. BMJ Open 2016;6:e011638.

10. Kishore MT, Nizamie A, Nizamie SH, Jahan M. Psychiatric diagnosis in persons with intellectual disability in India. J Intellect Disabil Res 2004;48:19-24.

11. McIntyre LL, Blacher J, Baker BL. Behaviour/mental health problems in young adults with intellectual disability: The impact on families. J Intellect Disabil Res 2002;46(Pt 3):239-49.

12. Hastings RP. Parental stress and behaviour problems of children with developmental disability. J Intellect Dev Disabil 2002;27:149-60.

13. Cooray S, Bhaumik S, Michael DM, Torales J, Ng R, Ventriglio A. Health promotion in people with intellectual disabilities. Int J Cult Ment Health 2016;9:430-3.

14. Robertson J, Emerson E, Hatton C, Yasamy MT. Efficacy of community-based rehabilitation for children with or at significant risk of intellectual disabilities in low - And middle-income countries: A review. J Appl Res Intellect Disabil 2012;25:143-54.

15. Lakhan R, Ekúndayò OT. Application of the ecological framework in depression: An approach whose time has come. AP J Psychol Med 2013;14:103-9.

16. Sen R, Goldbart J. Partnership in Action: Introducing family-based intervention for children with disability in urban slums of Kolkata, India. Intl J Disabil Dev Educ 2005;52:275-311.

This is an open access article distributed under the terms of the Creative Commons Attribution-NonCommercial-ShareAlike 3.0 License, which allows others to remix, tweak and build upon the work non-commercially, as long as the author is credited and the new creations are licensed under the identical terms.

\begin{tabular}{|l|l|}
\hline \multicolumn{2}{|c|}{ Access this article online } \\
\hline Quick Response Code: & Website: \\
& www.ruralneuropractice.com \\
\cline { 2 - 2 } & \\
\hline
\end{tabular}

How to cite this article: Lakhan R, Ekúndayò OT. Important research priorities in intellectual disability in India: A public health perspective. J Neurosci Rural Pract 2017;8:S150-1.

(c) 2017 Journal of Neurosciences in Rural Practice | Published by Wolters Kluwer - Medknow 